Original Article

\title{
The Comparison of Hearing Capabilities and Blood Pressure with Reference to Noise Pollution in Rural/Urban Areas of District Hyderabad
}

\author{
Tazeen Shah, Jamshed Warsi, Benazir Mahar, Shafaq Ansari
}

\begin{abstract}
OBJECTIVE: To compare the noise pollution and blood pressure in urban and or rural areas of Hyderabad, Sindh, Pakistan.

METHODOLOGY: A comparative cross sectional study was conducted from April 2018 to September 2018. The sample size was randomly selected 201 young adults of either gender between 18 to 25 years of age.

RESULTS: The hearing frequency in rural female $(29.34 \mathrm{~Hz} \pm 8.04)$ was significantly $(p<0.05)$ less than the urban female $(49.09 \mathrm{~Hz} \pm 7.76)$. Similarly, the hearing frequency in rural male $(24.72 \pm 7.0)$ was also significantly $(p=<0.05)$ less than that of urban group $(40.56 \mathrm{~Hz} \pm 7.6)$. The systolic and pulse pressure $(106.2 \mathrm{mmHg} \pm 4.35$ and $38.88 \mathrm{mmHg} \pm 4.8)$ was recorded significantly $(p=<0.05)$ lower in rural than Urban female (114.2mmHg \pm 6.03 and45.76 \pm 4.8$)$. Moreover, the systolic and pulse pressure

$(108.3 \mathrm{mmHg} \pm 5.40$ and $42.4 \mathrm{mmHg} \pm 4.71)$ was significantly $(p=<0.05)$ lower in rural than urban males $(114.2 \mathrm{mmHg} \pm 6.00$ and $47.33 \mathrm{mmHg} \pm 5.00 \mathrm{mmHg}$ ) respectively.

CONCLUSION: The study concludes that noise pollution has potent impact on hearing capabilities and blood pressure in urban areas of district Hyderabad, Sindh, Pakistan
\end{abstract}

KEYWORDS: Urbanization, noise pollution, hearing impairment, blood pressure.

This article may be cited as: Shah T, Warsi J, Mahar B, Ansari S. The Comparison of Hearing Capabilities and Blood Pressure with Reference to Noise Pollution in Rural/Urban Areas of District Hyderabad. J Liaquat Uni Med Health Sci. 2019;18(02):142-5.

doi: 10.22442/jlumhs.191820617

\section{INTRODUCTION}

Environmental noise hazards are increasing due to the burgeoning population in urbanized areas ${ }^{1}$. The long term exposure to permanent loud (traffic) noise is associated with health issues ${ }^{2}$. Particularly vulnerable individuals are those who are exposed to noise for a long time ${ }^{3}$. The health issues attributed to noise pollutions are: cardiovascular effects and blood pressure ${ }^{4,5}$. After age induced hearing loss ${ }^{6}$, noise induced hearing loss (NIHL) is the second common cause of hearing loss ${ }^{7}$, Noise exposure can lead to two kinds of health abnormalities known as nonauditory and auditory effects, stress, agitation, and other behavioral effects comes under non auditory ${ }^{8}$ whereas hearing impairment resulting from excessive noise exposure due to automobiles can be a major auditory effect ${ }^{9}$. When noise exposure continues for a longer duration of time, days turning to months and when person experience loud noises for prolonged period of time, it can lead to hearing disabilities, and the hearing impairment is obvious only when it is interfering with the routine activities. At this stage, an irreversible damage has occurred to hearing apparatus which is incurable and will be deteriorated more in case of continuous exposure noise ${ }^{10}$. Furthermore, noise induced hearing loss (NIHL) is the hearing impairment due to chronic exposure to loud sound. The pathology of NIHL includes the loss of hair cells in the Organ of Corti. Since hair cells do not regenerate, NIHL can be irreversible. Additionally, outer hair cells (OHCs) of cochlea are the sensory cells which are more affected to noise exposure than inner hair cells. The findings in NIHL include the destruction of OHCs, loss of supporting cells, organ of Corti damage, and loss of primary auditory nerve fibers $^{11}$

Moreover; Hypertension is one of the most important risk factor for morbidity and mortality ${ }^{12}$. Fluctuations in blood pressure (BP) may lead to many health issues. Recent researches suggested evidences of adverse effects of exposure to noise on blood pressure in adults ${ }^{13}$. Noise causes disturbed sleep, fluctuate blood pressure, heart rate and thus may increase in levels of stress hormone and oxidative stress, which in turn may result in endothelial dysfunction and high blood pressure $^{14}$. Hence; in order to find out the prevalence of hearing loss in urbanized areas and to evaluate the 
relationship between noise exposure and blood pressure fluctuations, this study was done.

\section{METHODOLOGY}

A survey based cross sectional study was conducted in Hyderabad city and Jamshoro, in collaboration with the department of Physiology, between April 2018 to September 2018, Sample size of 201 volunteers young adults (male/female) 18 to 25 years of age were selected randomly which were categorized into two groups, male and females, and were further categorized into rural and urban depending on their resident. Rural group had no exposure to loud sounds for $30 \mathrm{hrs} /$ week. Urban group includes residents near industrial and/or near busy road side, with the exposure to loud sounds for $30 \mathrm{hrs} /$ week, or habitual to frequent use of headphones/microphones for 30 hrs /week. Volunteers having history of chronic ear infection, ototoxicity by drugs, hypertension and diabetes mellitus, Patients of conductive deafness, Congenital anomaly of ear, and history of otic trauma were excluded from study. The study was conducted strictly under the ethical rules after approval from ERC University of Sindh Jamshoro.

Prior to experimentation, a written/signed consent was obtained, a self designed questionnaire for data collection was filled which included history, age, noise exposure and clinical examination.

Data are provided as Means \pm SD, and percentages; $\mathrm{n}$ represents the number of young male and/or female investigated. Data were assessed by using SPSS 21 (Statistical package for social sciences), Results were generated by using t- test, data with $p<0.05$ were considered statistically significant.

TEST PROTOCOL: Noise Measurement: The intensity of the noise pollution was measured in different areas of Hyderabad (Rural: Quiet, and Urban: Noisy) by using "Digital sound survey meter (Sound Level meter -4010)". The data was collected during day time at residential commercial, educational and silent zones. For recording the noise levels; the meter was bought towards the noisy area and was hold for 25 to 30 minutes for the measurement of noise. Furthermore, Whisper test, Rinne's test, Webber's test and Shawback test were performed on all young adult in order to exclude the possibilities of otic-trauma, infections and ear discharge.

The AUDIOMETRY was performed on audiometer (MAICO ${ }^{\circledR}$ MA-39 BERLIN GERMANY) at the power lab of department of physiology, Liaqat University of Medical and Health Sciences, Jamshoro.

For audiometry, instructions were given to volunteers about the procedure and how the subject is required to indicate (Volunteers were asked to raise a hand, press a button, or otherwise indicate when they could hear a sound) whether he / she can just hear or cannot hear a certain sound (the sound level may be increased from a very low level or reduced from a high level).moreover; volunteers were asked to remove anything (spectacles, earrings, hearing aids) which might disturb the test results. The earphones attached to the audiometer were adjusted carefully over the ears and the test was then carried out. The minimum intensity (volume) required hearing each tone was noted.

\section{RESULTS}

The current study explored the comparison of noise pollution in urbanized area of Hyderabad, Sindh, the study also focused on the association of noise pollution with hearing ability as well as blood pressure fluctuation. In this study, we randomly recruited 205 volunteers (male and/or female), Out of 205 four questionnaires were not filled properly / incomplete, thus were not included. The response was 201(98.04\%), out of 201 volunteers, 101(50.2\%) participant were the resident of rural areas while $100(49.8 \%)$ were urban residents, out of $101(50.2 \%)$ of rural population; $50(24.9 \%)$ were males and $51(25.4 \%)$ were females respectively, out of $100(49.8 \%)$ of urban volunteers $50(24.9 \%)$ were males, and $50(24.9 \%$ ) were females (As shown in Table I).

For the assessment of noise pollution; four highly noisy areas of the city were selected and the noise was measured, the average noise of the urban areas was recorded $85 \mathrm{db}$, similarly, for the assessment of noise in rural areas, measurements were carried out at four different places. The average intensity of noise was $38 \mathrm{db}$. Hence a significant difference was observed.

The ages of rural females $(21.81 \pm 2.07)$ and urban females (21.05 \pm 1.71$)$ and rural males (21.6 \pm 1.89$)$ years and Urban males $(21.31 \pm 1.67)$ was not found to be significant $(P=0.056, P=0.4$ respectively).

The hearing frequency in rural female $(29.34 \mathrm{~Hz} \pm 8.04)$ was significantly $(p=<0.05)$ less than the Urban female $(49.09 \mathrm{~Hz} \pm 7.76)$. Similarly, the hearing frequency in rural male $(24.72 \mathrm{~Hz} \pm 7.00)$ was also found to be significantly $(p=<0.05)$ less than that of urban group $(40.56 \mathrm{~Hz} \pm 7.6)$ shown in Table II and III.

The measurements of systolic blood pressure and pulse pressure $(106.2 \mathrm{mmHg} \pm 4.35$ and $38.88 \mathrm{mmHg}$ $\pm 4.8)$ was found significantly $(p=0.0001)$ lower than Urban areas (114.2 $\mathrm{mmHg} \pm 6.03$ and $45.76 \pm 4.8)$ however the diastolic blood pressure was not observed statistically $(p=0.4)$ different in rural $(67.32$ $\mathrm{mmHg} \pm 4.10)$ and Urban inhabitants $(68.45 \mathrm{mmHg}$ \pm 0.44 ) as shown in Table II and III. 
TABLE I:

AREA WISE DISTRIBUTION OF PARTICIPANT

\begin{tabular}{|l|c|c|c|}
\hline & Rural & Urban & $\begin{array}{c}\text { Total } \\
(\mathbf{n = 2 0 1 )}\end{array}$ \\
\hline Male & $50(24.9 \%)$ & $50(24.9 \%)$ & $100(49.8)$ \\
\hline Female & $51(25.4 \%)$ & $50(24.9 \%)$ & $101(50.2 \%)$ \\
\hline Total & $101(50.2 \%)$ & $100(49.8 \%)$ & $201(100 \%)$ \\
\hline
\end{tabular}

TABLE II: COMPARISON OF AGE, HEARING FREQUENCY AND BLOOD PRESSURE IN FEMALE PARTICIPANTS $(n=101)$

\begin{tabular}{|l|c|c|c|}
\hline \multicolumn{1}{|c|}{ Parameters } & Rural & Urban & $\boldsymbol{p}$-Value \\
\hline Age (years) & $21.81 \pm 2.07$ & $21.05 \pm 1.71$ & $>0.05$ \\
\hline Hearing frequency $(\mathrm{Hz})$ & $29.34 \pm 8.04$ & $49.09 \pm 7.76$ & $<0.05$ \\
\hline $\mathrm{BP}($ Systolic) $\mathrm{mmHg}$ & $106.2 \pm 4.35$ & $114.2 \pm 6.03$ & $<0.05$ \\
\hline $\mathrm{BP}($ Diastolic $) \mathrm{mmHg}$ & $67.32 \pm 4.10$ & $68.45 \pm 0.44$ & $>0.05$ \\
\hline Pulse pressure $(\mathrm{mmHg})$ & $38.88 \pm 4.8$ & $45.76 \pm 4.83$ & $<0.05$ \\
\hline
\end{tabular}

Hz: Hertz (international unit for frequency of sound), BP: Blood Pressure, $\mathrm{mmHg}$ : Mercuric millimeter

TABLE III: COMPARISON OF AGE, HEARING FREQUENCY AND BLOOD PRESSURE IN MALE PARTICIPANTS $(n=100)$

\begin{tabular}{|l|c|c|c|}
\hline \multicolumn{1}{|c|}{ Parameters } & Rural & Urban & $\boldsymbol{p}$-Value \\
\hline Age (years) & $21.6 \pm 1.89$ & $21.31 \pm 1.67$ & $>0.05$ \\
\hline Hearing frequency $(\mathrm{Hz})$ & $24.72 \pm 7.00$ & $40.56 \pm 7.65$ & $<0.05$ \\
\hline BP(Systolic) $\mathrm{mmHg}$ & $108.3 \pm 5.40$ & $114.2 \pm 6.00$ & $<0.05$ \\
\hline BP(Diastolic) $\mathrm{mmHg}$ & $66.26 \pm 4.73$ & $66.88 \pm 4.13$ & $>0.05$ \\
\hline Pulse pressure $(\mathrm{mmHg})$ & $42.4 \pm 4.71$ & $47.33 \pm 5.00$ & $<0.05$ \\
\hline
\end{tabular}

$\mathrm{Hz}$ : Hertz (international unit for frequency of sound), BP: Blood Pressure, $\mathrm{mmHg}$ : Mercuric millimeter

\section{DISCUSSION}

The present study reveals the comparison of hearing capabilities and blood pressure with reference to urbanization and traffic noise. As suggested by Lie A et $\mathrm{al}^{13}$ Traffic noise in many large cities of the world is greater than the suggested levels. Experiencing high levels of noise may cause deteriorating health impact like heart diseases and hearing. The hearing frequency in rural female and male (quiet areas with the noise intensity of $38 \mathrm{db}$ ) was significantly less than the urban female and male (highly noisy areas with the average sound intensity of $85 \mathrm{db}$ ). Hence the urbanization and heavy traffic noise is directly affecting the hearing capabilities of city dwellers. Munzel T $2014^{14}$ also suggests suggest that environmental noise is linked with an enhanced frequency of arterial hypertension, stroke and myocardial infarction. Furthermore; in order to eradicate the chance of aging and its association with hearing loss ${ }^{15}$ and blood pressure ${ }^{16}$ all the groups were taken from nearly same age. Thus the age is not a factor inducing hear loss in this specific study.

Additionally; the systolic blood pressure was significantly higher in urbanized noise exposed group as compared to quiet remote rural participant. The results are persistent with the work done previously suggesting in their study that SBP and DBP were significantly higher among the bus drivers when compared to the controls ${ }^{17}$. In another study it was observed that there was a highly significant positive correlation between hearing deficiency impairment (HDI) and years and exposure to noise ${ }^{18}$. Moreover; Pulse pressure was also recorded significantly higher in urban group in comparison to rural in male as well as in female which is a novel finding, As suggested by Balietti $P$ et $\mathrm{al}^{19}$ the rise in Pulse pressure with increase age shows stiffness of arteries due to arteriosclerosis the ambulatory Pulse pressure could possibly be a mortality predictor in old age people suffering from hypertension.

The impacts of noise pollution are inevitable due to heavy flooding of people towards cities in order to seek more civic amnesties (urbanization) and lack of public policy for traffic noise.

\section{CONCLUSION}

Prolonged and permanent exposure to high intensity noise could lead to compromised hearing capabilities and elevated blood pressure.

Ethical Permission: ERC approval letter of University of Sindh Reference No/Physio/261 dated: 20-02-2018.

Conflict of interest: There was no any conflict of interest.

Funding: There was no any funding agency.

\section{REFERENCES}

1. Salter CM, Ahn R, Yasin F, Hines R, Kornfield L, Salter EC, et al. Community Noise, Urbanization, and Global Health: Problems and Solutions. In: Ahn R, Burke T, McGahan A (eds). Innovating for Healthy Urbanization. Springer, Boston, MA. 2015; p. 165-92.

2. Munzel T, Sorensen M, Schmidt F, Schmidt E, Steven S, Kroller-Schon S, et al. The Adverse Effects of Environmental Noise Exposure on Oxidative Stress and Cardiovascular Risk. Antioxid Redox Signal. 2018; 28(9): 873-908. doi: $10.1089 /$ ars.2017.7118.

3. Singh A, Bansal A, Goel S, Goel PK, Chhitara P, 
Singh NK. A rapid appraisal of traffic policemen about auditory effects of traffic noise pollution from Ambala city. Med J Dr. D.Y. Patil Uni. 2015; 8(1): 12-15. doi: 10.4103/0975-2870.148826

4. Yang X, Jia X, Dong W, Wu S, Miller MR, Hu D, et al. Cardiovascular benefits of reducing personal exposure to traffic-related noise and particulate air pollution: A randomized crossover study in the Beijing subway system. Indoor Air. 2018; 28: 777786. doi.10.1111/ina.12485.

5. Hahad O, Beutel M, Gori T, Schulz A, Blettner M, Pfeiffer $\mathrm{N}$, et al. Annoyance to different noise sources is associated with atrial fibrillation in the Gutenberg Health Study. Int J Cardiol. 2018; 264:79-84. doi: 10.1016/j.ijcard.2018.03.126.

6. Johnson KR, Tian C, Gagnon LH, Jiang H, Ding D, Salvi R. Effects of Cdh23 single nucleotide substitutions on age-related hearing loss in C57BL/6 and 129S1/Sv mice and comparisons with congenic strains. Sci Rep. 2017; 7(1): 44450. doi: $10.1038 /$ srep44450.

7. Nandi SS, Dhatrak SV. Occupational noise-induced hearing loss in India. Indian $\mathrm{J}$ Occup Environ Med. 2008; 12(2): 53-6. doi: 10.4103/0019-5278.43260

8. Min JY, Min KB. Night noise exposure and risk of death by suicide in adults living in metropolitan areas. Depress Anxiety. 2018; 35(9): 876-883. doi: 10.1002/da.22789.

9. Nagodawithana NS, Pathmeswaran A, Pannila AS, Wickramasinghe AR, Sathiakumar N. Noise-induced hearing loss among traffic policemen in the City of Colombo, Sri Lanka. Asian J Water Environ Pollut. 2015; 12(3): 9-14. doi: 10.3233/AJW-150002.

10. Akter S, Hasan A, Fardous F, Bhouyain AM. Effect of noise pollution on hearing capacity of workers in Jute Mills of Chittagong City. Afr $\mathrm{J}$ Environ Sci Technol. 2018; 12(1): 15-20. doi:10.5897/AJEST2017.2432.

11. Natarajan K, Sudhamaheswari S, Murali S, Devarasetty A, Kameswaran M. Auditory effects of noise pollution: Current research and future trends. Ann Indian Acad Otorhinolaryngol Head Neck Surg. 2017; 1(1): 2-5. doi:10.4103/ aiao.aiao_3_16.

12. Maron $B \bar{A}$, Hess E, Maddox TM, Opotowsky AR,
Tedford RJ, Lahm T, et al. Association of Borderline Pulmonary Hypertension With Mortality and Hospitalization in a Large Patient Cohort: Insights From the Veterans Affairs Clinical Assessment, Reporting, and Tracking Program. Circulation. 2016; 133(13): 1240-8. doi: 10.1161/ CIRCULATIONAHA.115.020207.

13. Lie A, Skogstad M, Johannessen HA, Tynes $T$, Mehlum IS, Nordby KC, et al. Occupational noise exposure and hearing: a systematic review. Int Arch Occup Environ Health. 2016; 89(3): 351-72. doi: 10.1007/s00420-015-1083-5.

14. Münzel T, Gori T, Babisch W, Basner $M$. Cardiovascular effects of environmental noise exposure. Eur Heart J. 2014; 35(13): 829-36. doi: 10.1093/eurheartj/ehu030.

15. Hazan V, Tuomainen O, Tu L, Kim J, Davis C, Brungart $D$, et al. How do aging and age-related hearing loss affect the ability to communicate effectively in challenging communicative conditions? Hear Res. 2018; 369:33-41. doi:10.1016/j.heares. 2018.06.009.

16. Doleželová Š, Jíchová Š, Husková Z, Vojtíšková A, Kujal $P$, Hošková $L$, et al. Progression of hypertension and kidney disease in aging fawn-hooded rats is mediated by enhanced influence of renin-angiotensin system and suppression of nitric oxide system and epoxyeicosanoids. Clin Exp Hypertens. 2016; 38(7): 644-51.

17. Balaji R, Rajasegaran R, John NA, Venkatappa US. Hearing Impairment and High Blood Pressure among Bus Drivers in Puducherry. J Clin Diagn Res. 2016;10(2): CC08-CC10. doi: 10.7860/ JCDR/2016/17361.7199

18. Demirelli S, Degirmenci H, Fırtına S, Salcan I, Ermis $\mathrm{E}$, Duman $\mathrm{H}$, et al. Evaluation of heart rate variability and night-time blood pressure measurements in patients with idiopathic sudden sensorineural hearing loss. Eur Rev Med Pharmacol Sci. 2016; 20(4): 726-32.

19. Balietti P, Spannella F, Giulietti F, Rosettani G, Bernardi B, Cocci $G$, et al. Ten-year changes in ambulatory blood pressure: The prognostic value of ambulatory pulse pressure. J Clin Hypertens (Greenwich). 2018; 20(9): 1230-37. doi: 10.1111/ jch.13344.

AUTHOR AFFILIATION:

Dr. Tazeen Shah

Department of Physiology

Liaqat University of Medical and

Health Sciences (LUMHS)

Jamshoro, Sindh-Pakistan.

Email: shahtazeen@yahoo.com
Mr. Jamshed Warsi

Department of Physiology

University of Sindh

Jamshoro, Sindh-Pakistan.
Ms. Benazir Mahar
Department of Physiology
University of Sindh
Jamshoro, Sindh-Pakistan.

Dr. Shafaq Ansari

Department of Physiology

LUMHS, Jamshoro, Sindh-Pakistan. 